\title{
Editorial from the Editor-in-Chief
}

\section{The International Year of Astronomy}

The United Nations Educational, Scientific and Cultural Organization (UNESCO) have proclaimed the year 2009 to be the International Year of Astronomy, and the International Astronomical Union is coordinating related events throughout this year.

When in 1609 , Galileo Galilei first turned his telescopes to the night sky he made striking observations that changed not only the perspective of scientists but practically everybody's conception about the way the universe we live in functions. Moreover his experimental approach to science together with the mandate of precise observation and measurement started science as we know it today. Today new instruments are launched into the sky and help us to understand processes that have been mysteries for a long time. Only few of the scientists in our field take an active part in satellite missions, however our instruments like high power lasers (Cook et al., 2008; Krasa et al., 2009; Neumayer et al., 2005; Nobile et al., 2006; Seifter et al., 2009), intense particle beam accelerators (Hoffmann et al., 2005; Kulagin et al., 2008; Ni et al., 2008; Singh et al., 2008), and pulsed power drivers (Burdovitsin \& Oks, 2008; Li et al., 2008; Liu et al., 2008; Mao et al., 2009; Tarasenko et al., 2008) can generate matter in extreme conditions. Usually, we find these conditions to prevail in the interior of stars, in stellar atmospheres, in interplanetary space, or even in the interior of planets. With lasers, accelerators, and pulsed power drivers we are able to generate high energy density matter under controlled and reproducible conditions and thus we investigate astrophysical phenomena in the laboratory. In this way, laboratory astrophysics becomes an important part of high energy density science. Many of the effects that have been observed by astronomers using telescopes can now be simulated in laboratory experiments. In this way, we are an active part of the international year of astronomy. Laser and Particle Beams has followed the development of laboratory astrophysics since 1998 (Browne, 1988; Rose, 1991). Currently, the investigation of laboratory plasma jets in comparison to astrophysical jets has become an interesting object for theoretical and experimental investigation (Kasperczuk et al., 2009; Schaumann et al., 2005; Schopper et al.,
2003; Sizyuk et al., 2007). We encourage our authors to continue to submit articles related to high energy density physics and laboratory astrophysics.

Finally, I want to make our community aware of two conferences later this year that are of importance to our community. From August 24-28, 2009 the 4th Stimulated Brillouin Scattering and Phase Conjugation Workshop will be held in Prague, Czech Republic. Laser and Particle Beams is following the developments in this field very closely and last year we carried a long article on trends in Brillouin scattering and phase conjugation (Kappe et al., 2007; Kong et al., 2007; Ostermeyer et al., 2008). The main event this year will be the Sixth International Conference on Inertial Fusion Sciences and Applications to be held September 6-11, 2009.

\section{REFERENCES}

Browne, P.F. (1988). Acceleration in the plasma-focus and in astrophysics. Laser Part. Beams 6, 409-420.

Burdovitsin, V.A. \& OKs, E.M. (2008). Fore-vacuum plasmacathode electron sources. Laser Part. Beams 26, 619-635.

Cook, R.C., Kozioziemski, B.J., Nikroo, A., Wilkens, H.L., Bhandarkar, S., Forsman, A.C., Haan, S.W., Hoppe, M.L., Huang, H., Mapoles, E., Moody, J.D., Sater, J.D., Seugling, R.M., Stephens, R.B., Takagi, M. \& Xu, H.W. (2008). National Ignition Facility target design and fabrication. Laser Part. Beams 26, 479-487.

Hoffmann, D.H.H., Blazevic, A., Ni, P., Rosmej, O., Roth, M., Tahir, N.A., Tauschwitz, A., Udrea, S., Varentsov, D., WeYrich, K. \& Maron, Y. (2005). Present and future perspectives for high energy density physics with intense heavy ion and laser beams. Laser Part. Beams 23, 47-53.

Kappe, P., Strasser, A. \& Ostermeyer, M. (2007). Investigation of the impact of SBS-parameters and loss modulation on the mode locking of an SBS-laser oscillator. Laser Part. Beams 25, $107-116$.

Kasperczuk, A., PisarczyK, T., Nicolai, P.H., Stenz, C.H., Tikhonchuk, V., Kalal, M., Ullschmied, J., Krousky, E., Masek, K., Pfeifer, M., Rohlena, K., Skala, J., Klir, D., Kravarik, J., Kubes, P. \& PisarczyK, P. (2009). Investigations of plasma jet interaction with ambient gases by multi-frame 
interferometric and X-ray pinhole camera systems. Laser Part. Beams 27, 115-122.

Kong, H.J., Yoon, J.W., Beak, D.H., Shin, J.S., Lee, S.K. \& Lee, D.W. (2007). Laser fusion driver using stimulated Brillouin scattering phase conjugate mirrors by a self-density modulation. Laser Part. Beams 25, 225-238.

Krasa, J., Velyhan, A., Jungwirth, K., Krousky, F., Laska, L., Rohlena, K., Pfeifer, M. \& Ullschmied, J. (2009). Repetitive outbursts of fast carbon and fluorine ions from sub-nanosecond laser-produced plasma. Laser Part. Beams 27, 171-178.

Kulagin, V.V., Cherepenin, V.A., Hur, M.S., Lee, J. \& Suk, H. (2008). Evolution of a high-density electron beam in the field of a super-intense laser pulse. Laser Part. Beams 26, 397-409.

Li, G.L., Yuan, C.W., Zhang, J.Y., Shu, T. \& Zhang, J. (2008). A diplexer for gigawatt class high power microwaves. Laser Part. Beams 26, 371-377.

Liu, R., Zou, X., Wang, X., He, L. \& Zeng, N. (2008). X-pinch experiments with pulsed power generator (PPG-1) at Tsinghua University. Laser Part. Beams 26, 33-36.

Mao, Z., Zou, X., Wang, X., Liu, X. \& Jiang, W. (2009). Circuit simulation of the behavior of exploding wires for nano-powder production. Laser Part. Beams 27, 49-55.

Neumayer, P., Bock, R., Borneis, S., Brambrink, E., Brand, H., Caird, J., Campbell, E.M., Gaul, E., Goette, S., Haefner, C., Hahn, T., Heuck, H.M., Hoffmann, D.H.H., Javorkova, D., Kluge, H.J., Kuehl, T., Kunzer, S., Merz, T., Onkels, E., Perry, M.D., Reemts, D., Roth, M., Samek, S., Schaumann, G., Schrader, F., Seelig, W., Tauschwitz, A., Thiel, R., Ursescu, D., Wiewior, P., Wittrock, U. \& Zielbauer, B. (2005). Status of PHELIX laser and first experiments. Laser Part. Beams 23, 385-389.

Ni, P.A., Kulish, M.I., Mintsev, V., Nikolaev, D.N., Ternovoi, V.Y., Hoffmann, D.H.H., Udrea, S., Hug, A., Tahir, N.A. \& VARENTSOV, D. (2008). Temperature measurement of warm-dense-matter generated by intense heavy-ion beams. Laser Part. Beams 26, 583-589.

Nobile, A., Nikroo, A., Cook, R.C., Cooley, J.C., Alexander, D.J., Hackenberg, R.E., Necker, C.T., Dickerson, R.M., Kilkenny, J.L., Bernat, T.P., Chen, K.C., Xu, H., Stephens, R.B., Huang, H., HaAn, S.W., Forsman, A.C., Atherton, L.J., LetTs, S.A., Bono, M.J. \& Wilson, D.C. (2006). Status of the development of ignition capsules in the US effort to achieve thermonuclear ignition on the national ignition facility. Laser Part. Beams 24, 567-578.

Ostermeyer, M., Kong, H.J., Kovalev, V.I., Harrison, R.G., Fotiadi, A.A., Megret, P., Kalal, M., Slezak, O., Yoon, J.W., Shin, J.S., BeAK, D.H., LeE, S.K., Lu, Z., WANG, S., Lin, D., Knight, J.C., Kotova, N.E., Straber, A., Scheikh-Obeid, A., Riesbeck, T., Meister, S., Eichler, H.J., Wang, Y., He, W., Yoshida, H., Fujita, H., Nakatsuka, M., Hatae, T., Park, H., Lim, C., Omatsu, T., Nawata, K., Shiba, N., Antipov, O.L., Kuznetsov, M.S. \& ZaKharov, N.G. (2008). Trends in stimulated Brillouin scattering and optical phase conjugation. Laser Part. Beams 26, 297-362.

Rose, S.J. (1991). High-power laser-produced plasma and astrophysics. Laser Part. Beams 9, 869-879.

Schaumann, G., Schollmeier, M.S., Rodriguez-Prieto, G., Blazevic, A., Brambrink, E., Geissel, M., Korostiy, S., Pirzadeh, P., Roth, M., Rosmej, F.B., Faenov, A.Y., Pikuz, T.A., Tsigutkin, K., Maron, Y., Tahir, N.A. \& Hoffmann, D.H.H. (2005). High energy heavy ion jets emerging from laser plasma generated by long pulse laser beams from the NHELIX laser system at GSI. Laser Part. Beams 23, $503-512$.

Schopper, R., Ruhl, H., KunZl, T.A. \& Lesch, H. (2003). Kinetic simulation of the coherent radio emission from pulsars. Laser Part. Beams 21, 109-113.

Seifter, A., Kyrala, G.A., Goldman, S.R., Hoffman, N.M., Kline, J.L. \& BATHA, S.H. (2009). Demonstration of symcaps to measure implosion symmetry in the foot of the NIF scale 0.7 hohlraums. Laser Part. Beams 27, 123-127.

Singh, K.P., SAJAL, V. \& GuPTA, D.N. (2008). Quasi-monoenergetic $\mathrm{GeV}$ electrons from the interaction of two laser pulses with a gas. Laser Part. Beams 26, 597-604.

Sizyuk, V., Hassanein, A. \& Sizyuk, T. (2007). Hollow laser selfconfined plasma for extreme ultraviolet lithography and other applications. Laser Part. Beams 25, 143-154.

Tarasenko, V.F., Baksht, E.H., Burachenko, A.G., Kostyrya, I.D., Lomaev, M.F. \& RybKa, D.V. (2008). Supershort avalanche electron beam generation in gases. Laser Part. Beams 26, 605-617. 